\title{
Benefits from clinicians and healthcare organisations engaging in research
}

\author{
Stephen Hanney emeritus professor ${ }^{1}$, Bryony Soper honorary professor ${ }^{1}$, Teresa Jones research \\ fellow ${ }^{1}$, Annette Boaz professor of health care research ${ }^{2}$
}

${ }^{1}$ Health Economics Research Group, Brunel University London, Uxbridge UB8 3PH, UK; ${ }^{2}$ St George's, University of London and Kingston University, London, UK

In Editor's Choice, Godlee supports and re-emphasises the positive points about National Institute for Health Research (NIHR) clinical research networks that are made in Gulland's article. ${ }^{12}$ We welcome this support for research networks and for the part they can play in a more fully integrated research and healthcare system.

Research engagement by clinicians and healthcare organisations is widely held to improve health services performance. However, we found the issue to be complex in our review conducted for the NIHR Health Services and Delivery Research (HS\&DR) Programme in 2012-13. ${ }^{3}$ Thirty three papers were included in the analysis, and 28 were positive about improved performance, although only seven identified improved outcomes rather than improved processes. Diverse mechanisms contributed to these improvements. In a subsequent article we consider more recent evidence, ${ }^{4}$ including that UK NHS trusts active in research have lower risk adjusted mortality for acute admissions. ${ }^{5}$

Increased attention to this issue covers not only clinician participation but also organisational developments in the NIHR and NHS, such as Collaborations for Leadership in Applied Health Research and Care (CLAHRC) and Academic Health Science Networks (AHSNs). ${ }^{67}$ These seek to promote better integration of research and healthcare systems by strengthening research networks, developing research capacity, and ensuring that healthcare organisations (both providers and commissioners) see research as an integral component of their overall structure. Such initiatives need to be linked to further empirical analysis that considers not only the research engagement of all relevant actors but also the organisational determinants of the impact on practice of such engagement.

Competing interests: None declared.

Full response at: www.bmj.com/content/351/bmj.h6525/rr-5.

Godlee F. Research is the future: get involved. [Editor's Choice]. BMJ 2015;351:h6525. (3 December.)

2 Gulland A. "It's the duty of every doctor to get involved with research." $B M J$ 2015;351:h6329. (27 November.)

3 Hanney S, Boaz A, Jones T, et al. Engagement in research: an innovative three-stage review of the benefits for healthcare performance. Health Serv Deliv Res 2013;1(8).

4 Boaz A, Hanney S, Jones T, et al. Does the engagement of clinicians and organisations in research improve healthcare performance: a three-stage review. BMJ Open 2015;5:e009415 doi:10.1136/bmjopen-2015-009415.

5 Ozdemir BA, Karthikesalingam A, Sinha S, et al. Research activity and the association with mortality. PLOS ONE 2015;10:e0118253.

6 Soper B, Hinrichs S, Drabble S, et al. Delivering the aims of the Collaborations for Leadership in Applied Health Research and Care: understanding their strategies and contributions. Health Serv Deliv Res 2015;3(25).

7 AHSN Network. Spreading innovation, improving health, promoting economic growth. AHSN Impact Report 2015. www.ahsnnetwork.com/wp-content/uploads/2014/12/AHSNsimpact-report-2015.pdf.

Cite this as: BMJ 2015;351:h6931

๑ BMJ Publishing Group Ltd 2015 